This item was submitted to Loughborough's Research Repository by the author.

Items in Figshare are protected by copyright, with all rights reserved, unless otherwise indicated.

\title{
Comparison of carbon dioxide emissions for two landfill capping layers
}

\section{PLEASE CITE THE PUBLISHED VERSION}

http://dx.doi.org/10.1680/ensu.14.00006

\section{PUBLISHER}

(C) Thomas Telford (ICE Publishing)

\section{VERSION}

VoR (Version of Record)

\section{PUBLISHER STATEMENT}

This work is made available according to the conditions of the Creative Commons Attribution-NonCommercialNoDerivatives 4.0 International (CC BY-NC-ND 4.0) licence. Full details of this licence are available at: https://creativecommons.org/licenses/by-nc-nd/4.0/

\section{LICENCE}

CC BY-NC-ND 4.0

\section{REPOSITORY RECORD}

Raja, Jamil, Neil Dixon, Gary John Fowmes, Matthew W. Frost, and Peter Assinder. 2019. "Comparison of Carbon Dioxide Emissions for Two Landfill Capping Layers". figshare. https://hdl.handle.net/2134/19782. 


\section{Comparison of carbon dioxide emissions for two landfill capping layers}

1 Jamil Raja BEng(Hons) Research Engineer, Department of Civil and Building Engineering, Loughborough University, Loughborough, UK

2. Neil Dixon PhD, FGS

Professor of Geotechnical Engineering, Department of Civil and Building Engineering, Loughborough University, Loughborough, UK

3 Gary Fowmes MSc, EngD

Lecturer in Engineering Geology, Department of Civil and Building Engineering, Loughborough University, Loughborough, UK
$4 \quad$ Matthew Frost PhD, MPWI

Lecturer in Geotechnical Engineering, Department of Civil and Building Engineering, Loughborough University, Loughborough, UK

5 Peter Assinder MSc, FGS, CGeol, CSci

Chairman, UK Chapter of International Geosynthetics Society; Area Manager Africa, Huesker Synthetic GmbH, Gescher, Germany
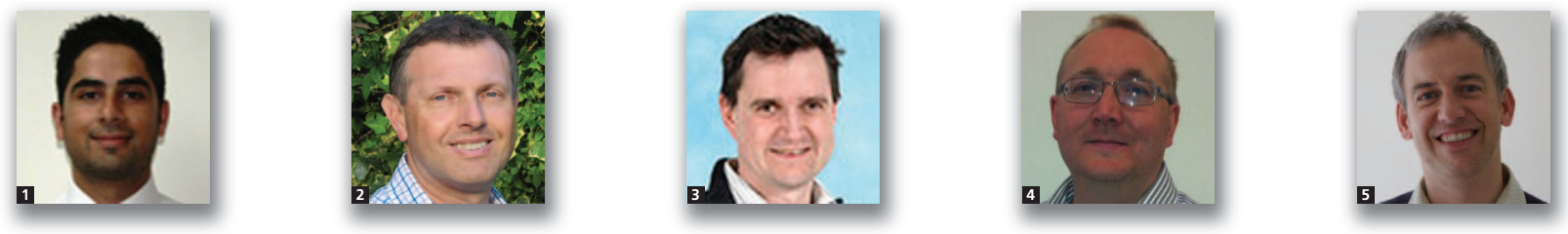

Geosynthetics are commonly employed in landfill applications to provide containment in the capping layer, also referred to as a cover system. This paper presents a case study that compared the carbon dioxide emissions produced from a compacted clay landfill cap with one incorporating geosynthetics. The lifecycle analysis boundaries set for the case study were cradle to end-of-construction, and included all processes from sourcing of materials through to the end-of-construction. As-built data provided by contractors and manufacturers were used to calculate the carbon footprint of each solution and the comparison showed the geosynthetic solution to be more sustainable. However, deficiencies in standard database values revealed inconsistencies and a value for the embodied carbon of clay was calculated using primary data. The embodied carbon value calculated from the primary data was much lower than the one initially employed and hence made the clay solution more sustainable where materials were locally available.

$\begin{array}{ll}\text { Notation } & \\ C & \text { total carbon dioxide emissions }(\mathrm{t}) \\ D & \text { distance of transportation }(\mathrm{km}) \\ T & \text { truckloads of materials }(=Q / 20) \\ Q & \text { quantity of material }(\mathrm{t}) \\ \alpha & \text { fuel consumption of rigid heavy goods } \\ \beta & \text { vehicle } \\ \beta & \text { carbon dioxide emissions per litre of fuel }\end{array}$

\section{Introduction}

The issues surrounding sustainability are at the forefront of modern-day engineering. There has been considerable research into approaches that can produce more sustainable designs and construction processes with a growing demand for such solutions. The UK government has recognised this need by producing strategies for sustainable construction (BERR, 2008) and creating groups such as the Innovation and Growth Team (IGT) to look at ways in which the construction industry can meet the agreed sustainable low-carbon agenda (IGT, 2010). In the context of this paper the term sustainability is defined as ways of reducing carbon dioxide emissions, covering key aspects of the construction sequence from sourcing and transportation, to the reuse and wastage of materials.
There is significant scientific evidence that links greenhouse gases (GHGs) and carbon dioxide emissions with the changing climate. Increases in carbon dioxide emissions have been accompanied by global temperature rises, with the period 2000-2009 being the warmest decade on record (Royal Society, 2010). This changing climate has forced many nations and governments worldwide to take action to curb the emissions of carbon dioxide and other GHGs. The UK government passed 
Engineering Sustainability

Volume 167 Issue ES5
Comparison of carbon dioxide

emissions for two landfill

capping layers

Raja, Dixon, Fowmes, Frost and

Assinder legislation in one of the world's first long-term frameworks to tackle the problems associated with climate change: the Climate Change Act 2008 (2008) introduced a legally binding target to reduce UK GHG emissions by at least $80 \%$ below base year (1990) levels by 2050 .

The construction sector is responsible for influencing $47 \%$ of the UK's total carbon dioxide emissions (BIS, 2010) and therefore is one of the sectors where action is required to reduce emissions. Although the UK legislation does not specifically target individual construction projects, Construction 2025 (BIS, 2013) sets out a vision and a plan for long-term strategic action by both government and industry. The plan includes the target of reducing GHG emissions from the construction sector by $50 \%$ by 2015 . This is raising awareness among clients, consultants and contractors, leading to an increased level of research and acting as a powerful driver for utilising more sustainable, reduced carbon dioxide, construction solutions. One particular solution that has been shown to provide carbon dioxide reduction benefits is the use of geosynthetics, which often lessens the amount of fill material that needs to be imported. Wrap (2010) highlighted carbon dioxide and cost savings from the use of geosynthetics, but the scope of this work was mainly limited to soil reinforcement applications. Work by the European Association of Geosynthetic Manufacturers (EAGM) covered a wider range of applications and functions and also highlighted the environmental benefits of geosynthetics (Stucki et al., 2011). An example of an application covered by the EAGM study is the use of geosynthetics in landfill cover systems. The benefits of these systems were discussed by Heerten
(2012), along with lifecycle analysis (LCA) studies that also provided detailed comparisons of climate-damaging gases produced by non-geosynthetic and geosynthetic solutions. However, the published studies comparing the carbon dioxide emissions produced by geosynthetic and non-geosynthetic solutions have limitations as they do not explicitly consider the source and accuracy of a material's embedded carbon dioxide and they employ inconsistent LCA boundary conditions.

The construction of landfill capping layers can be carried out by means of a number of different solutions. Effective containment provided by the capping layer reduces infiltration and associated leachate production, and enhances the production and harvesting of bio-gases that can be used as a renewable energy source (Popov, 2005). The capping layer and its effective design can therefore provide both economic and sustainability benefits. There are a number of commonly employed solutions that use either clay or a combination of geosynthetics as an effective containment layer (Koerner and Daniel, 1997). Figure 1 shows a typical section of the geosynthetic-based capping layer applied in the project used in this case study and a commonly employed clay-based alternative. The choice of which solution to apply varies from site to site, and is dependent on factors such as design, economics, materials availability and the timeframe available for construction.

This paper reports on a LCA case study that compared the environmental impact - in terms of carbon dioxide emissions of the two solutions illustrated in Figure 1. A number of different LCA criteria can be used, depending on both the

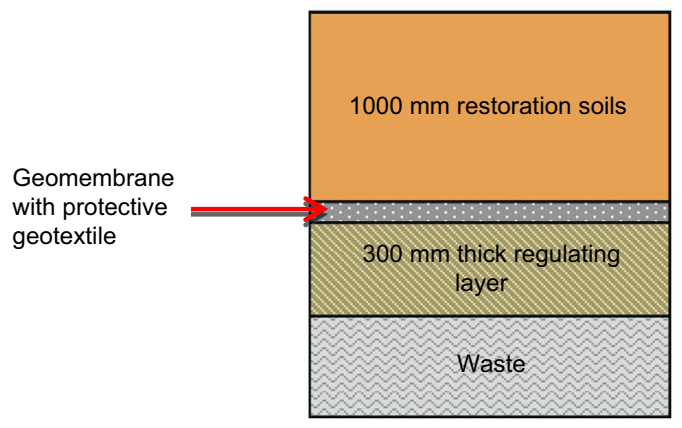

(a)

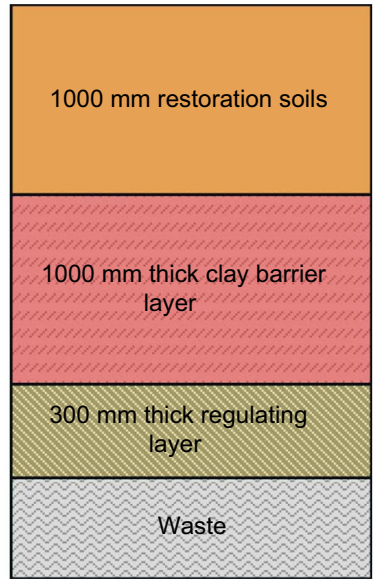

(b)

Figure 1. Typical section of (a) original design involving geosynthetic-based capping layer employed in the project and (b) alternative design that could be employed, involving a $1 \mathrm{~m}$ thick clay layer to replace the geosynthetic layer 
Engineering Sustainability

Volume 167 Issue ES5
Comparison of carbon dioxide

emissions for two landfill

capping layers

Raja, Dixon, Fowmes, Frost and

Assinder input information and the system boundaries and requirements. Previous Wrap case studies (Wrap, 2010) included all the emissions produced, from sourcing of materials to the transportation of materials to site. This included extraction, manufacture and delivery to site, and can be classed as a cradle to site LCA system boundary. Clear and concise system LCA boundaries are critical in any evaluation and ensure that likefor-like comparisons are made (Figure 2). Examples of how different LCA criteria have been employed in carbon dioxide emissions research for other applications can be found in the works carried out by Crishna et al. (2011) and Kiani et al. (2008). Crishna et al. (2011) employed system boundaries of cradle to site for a study of UK dimension stone, whereas Kiani et al. (2008) report on a study of railway track beds using an extended scope of cradle to grave, which also included the reuse of materials.

The LCA boundaries employed in this case study were cradle to end-of-construction. The two capping solutions were assumed to have equivalent performance as a containment barrier, hence the 'use' and 'end-of-life' stages of the LCA were not considered in this study. This assumption is also justified by a study of the performance of different cover system solutions reported by Heerten and Koerner (2008). Therefore, for this case study, the total carbon dioxide emissions calculated included embodied carbon, the transport of materials and construction-related emissions. The results obtained provided a comparison of the carbon dioxide emissions produced by the two solutions. The comparison indicates which solution would be more sustainable in terms of carbon dioxide emissions and highlights how input data can affect overall results. It was not in the scope of this study to include costs but, as noted in previous research (Wrap, 2010), there can be significant cost benefits in employing the more sustainable solution.

\section{Case study details}

The case study was based on a landfill site situated in the southeast of England. The study focused on the capping of one landfill cell, covering an area of $9572 \mathrm{~m}^{2}$, and compared the carbon dioxide emissions produced by the actual geosyntheticbased design employed and an alternative clay design (see Figure 1). The selected site was chosen as both clay and geosynthetic solutions had been used to cap different landfill phases over the life of the site and the clay solution was thus a credible alternative. The LCA study carried out was a carbon dioxide comparison, and not necessarily the total carbon dioxide footprint of each project. Therefore, the emissions associated with compatible activities used in both solutions (e.g. setup of the site, transport of machinery, operation of site cabins and welfare) were omitted.

The quantities of materials required for the project are listed in Table 1. Only those materials that were considered in the scope of this comparative study are listed; hence material data of the regulatory layer and restoration soils are not included as they are the same for both design options. As-built construction data and manufacturers' data were used to calculate the total amount of geosynthetic and clay materials required in the capping solutions. Use of such first-hand data was maintained throughout the study and in all the LCA stages: embodied carbon and transport-related and construction-related emissions.

\section{Embodied carbon}

The first stage of the calculation process was to quantify the embodied carbon of the materials employed. This accounts for all the carbon dioxide emissions associated with the production of the materials up until they are ready to leave the factory site. The embodied carbon values were sourced directly from the University of Bath Inventory of Carbon \& Energy (Hammond

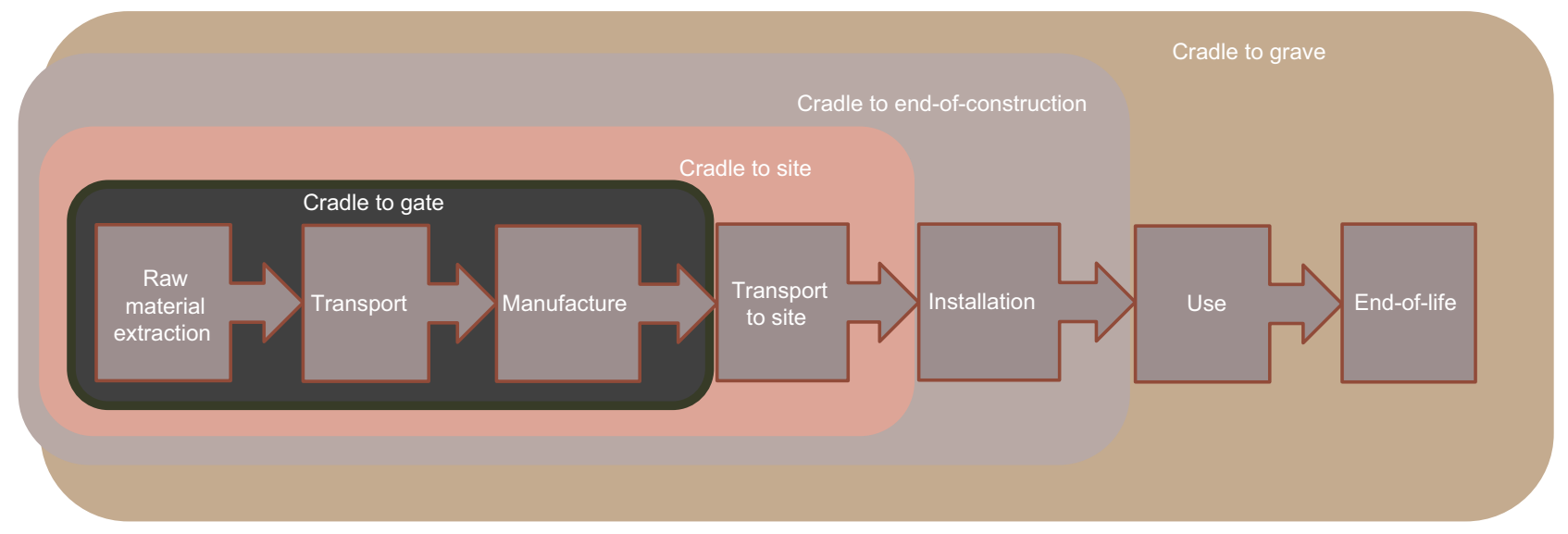

Figure 2. Lifecycle boundaries 
Engineering Sustainability

Volume 167 Issue ES5
Comparison of carbon dioxide

emissions for two landfill

capping layers

Raja, Dixon, Fowmes, Frost and

Assinder

\begin{tabular}{lcccc} 
Material & Area required: $\mathrm{m}^{2}$ & Mass: $\mathrm{kg} / \mathrm{m}^{2}$ & Bulk density: $\mathrm{Mg} / \mathrm{m}^{3}$ & Quantity: $\mathrm{t}$ \\
\hline Geomembrane & 9572 & 0.939 & - & 8.99 \\
Geotextile & 9572 & 0.320 & - & 3.06 \\
Clay & 9572 & - & $2 \cdot 00$ & 19144
\end{tabular}

Table 1. Quantities of geosynthetics and clay required

and Jones, 2008a). The Inventory of Carbon \& Energy database was developed with the construction industry in mind and it thus includes over 1700 embodied energy records covering a range of materials from aggregates to concrete and steel. This is the most comprehensive database of its kind and the preferred source of data for LCA analyses carried out in the UK. The Wrap report and calculations (Wrap, 2010) also employed data from the Inventory of Carbon \& Energy database. However, as with any lifecycle inventory, there are a number of assumptions. For example, Hammond and Jones (2008b) describe how differences in manufacturing processes and assumptions based on the fuel mixes can create a natural variation in the embodied carbon coefficients, and values must be used cautiously.

The geomembrane and geotextile employed in the geosynthetic solution have different embodied carbon values. The geomembrane used was formed from linear low density polyethylene whereas the geotextile was manufactured from polypropylene. In the alternative design, an embodied carbon value for the clay was also required. With no specific embodied carbon value for clay in the Inventory of Carbon \& Energy database, a value of quarried aggregate was assumed as the most representative; this assumption is revisited in Section 7 of this paper. The embodied carbon values used from the Inventory of Carbon \& Energy database as well as the total carbon dioxide emissions produced by these materials are given in Table 2 .

\section{Transport emissions}

The calculated embodied carbon accounted for all the carbon dioxide emissions up to the point of materials leaving the factory site: in terms of LCA, this would be classed as cradle to gate values. In order to progress the LCA to the next stage of gate to site, transport-related emissions need to be accounted for. The as-built data were used to acquire accurate transport distances. In the case of the geomembrane, which is commonly imported from Europe, the manufacturer was contacted for details of the route and transportation methods. Table 3 provides the transport distances.

The amount of fuel consumed and subsequently the carbon dioxide emissions produced were then calculated from the data in Table 3. Using data from previous work (Wrap, 2010) along with information from contractors and materials suppliers, a rigid $20 \mathrm{t}$ vehicle was assumed as the road transport mechanism. The fuel consumption of one truck in conjunction with the carbon dioxide emissions produced per litre of fuel was used to calculate the total emissions from the road transport of materials. Road freight statistics (DfT, 2012) provided an average value of $9 \cdot 4$ miles per gallon for a $17 \cdot 5-25 \cdot 0 \mathrm{t}$ rigid heavy goods vehicle, which is equivalent to $3.33 \mathrm{~km} / 1$. The emissions value for fuelling station diesel is $2.5725 \mathrm{~kg}$ carbon dioxide per litre of fuel (Defra, 2011). Table 4 shows the total carbon dioxide emissions for the road transport of the materials. The distances stated in Table 4 are for a single journey and were multiplied by two in the calculations (Equation 1) to account for truck round trips. The total carbon dioxide emissions were thus calculated from

1. $C=\frac{[(2 D T) / \alpha] \beta}{1000}$

The transport route of the geomembrane also involved a ferry crossing to the UK from mainland Europe, which generated

\begin{tabular}{|c|c|c|c|}
\hline & \multicolumn{2}{|c|}{ Original design } & \multirow{2}{*}{$\begin{array}{c}\text { Alternative design } \\
\text { Clay }\end{array}$} \\
\hline & Geomembrane & Geotextile & \\
\hline Embodied carbon: $\mathrm{kg} \mathrm{CO} 2 \mathrm{e} / \mathrm{kg}$ & $2 \cdot 08$ & $3 \cdot 43$ & 0.005 \\
\hline Quantity: $t$ & $8 \cdot 99$ & $3 \cdot 06$ & 19144 \\
\hline Carbon dioxide emissions: $t$ & $18 \cdot 70$ & $10 \cdot 50$ & - \\
\hline Total carbon dioxide emissions: $t$ & \multicolumn{2}{|c|}{$29 \cdot 20$} & $95 \cdot 72$ \\
\hline
\end{tabular}

Table 2. Total embodied carbon of materials 


\begin{tabular}{lccccc} 
Material & Method 1 & Distance: $\mathrm{km}$ & Method 2 & Distance: km & Total: km \\
\hline Geomembrane & Freight & $368 \cdot 5$ & Ferry & $201 \cdot 2$ & $569 \cdot 7$ \\
Geotextile & Freight & $217 \cdot 3$ & - & - & $217 \cdot 3$ \\
Clay & Freight & 3.5 & - & - & $3 \cdot 5$
\end{tabular}

Table 3. Material transport distances

additional carbon dioxide emissions. These were calculated by again consulting data provided by Defra (2011). The average value for ferry transport of $0 \cdot 05136 \mathrm{~kg}$ carbon dioxide per tonne per kilometre was used in combination with the transport distance of $201.2 \mathrm{~km}$ and a geomembrane quantity of $8.99 \mathrm{t}$ to give the overall emissions for this phase of the travel. The calculations showed that the water transport phase produced $0 \cdot 18 \mathrm{t}$ carbon dioxide. The total transport emissions of the geomembrane were thus $0.75 \mathrm{t}$ carbon dioxide combined with $0.34 \mathrm{t}$ for the geotextile, giving a total of $1.09 \mathrm{t}$ carbon dioxide for the geosynthetic solution. Equation 1 gives a value of $5 \cdot 24 \mathrm{t}$ carbon dioxide for the alternative clay solution (Table 4).

\section{Construction emissions}

The scope of this case study also included the carbon dioxide emissions that would arise from the construction phase of the project. Similar to the decision to not include some materials in the embodied carbon and transport calculations due to them being common to both solutions, there were also some construction processes that were not included (e.g. unloading). A significant difference in placement techniques used was related to the amount of compaction required to the different layers employed in the two design solutions. Construction of the two solutions would require varying amounts of compaction effort and hence a large difference in the fuel consumed by the roller employed. The difference in compaction effort is because a clay barrier layer has to be compacted to achieve the required permeability, whereas the deployment of geosynthetics requires limited effort. However, in the geosynthetic solution, the regulatory layer requires more compaction effort than the clay solution in order to prepare the layer for the placement of the geosynthetics. In order to calculate carbon dioxide emissions, it was thus important to determine the compaction effort of the vibratory roller employed. Communications with the contractor and analysis of technical data sheets of the manufacturer of the compaction plant (Bomag, 2013) provided a compaction effort of $250 \mathrm{~m}^{3} / \mathrm{h}$. Table 5 illustrates how this compaction effort, in combination with other data, was used to calculate the total carbon dioxide emissions produced in construction.

Carbon dioxide emissions from the compaction phase of the clay solution were $10.40 \mathrm{t}$, compared with $1.89 \mathrm{t}$ for compaction of the regulatory layer in the geosynthetic solution. Although carbon dioxide emissions from fusion welding of the geomembrane were envisaged to have very little effect on the overall results, these were also calculated for completeness. Data for the diesel generator (Hardy Diesel, 2013) and the fusion welder (Silicon Instrumentation, 2013) were used to calculate the total fuel consumed for this phase of work (Table 6), and calculated to produce $0.03 \mathrm{t}$ carbon dioxide. As expected, this is a very small amount, accounting for just $1 \cdot 5 \%$ of the total construction carbon dioxide emissions produced by the geosynthetic solution $(1.92 \mathrm{t})$.

\section{Results and findings}

The results show that the geosynthetic solution produced significantly lower carbon dioxide emissions than if an alternative clay solution had been employed. In both solutions, the embodied carbon contributes the most towards overall carbon dioxide emissions, although construction and transport phases also make a significant contribution and highlight the need for the inclusion of the construction phase in LCA studies (Table 7 and Figure 3).

The contribution of both construction- and transport-related emissions is higher in the clay solution than in the geomembrane

\begin{tabular}{lccccc}
\hline Material & Quantity: $t$ & Distance: $k m$ & Truckloads & Fuel consumption: I & $\begin{array}{c}\text { Carbon dioxide } \\
\text { emissions: } t\end{array}$ \\
\hline Geomembrane & $8 \cdot 99$ & $368 \cdot 5$ & 1 & $221 \cdot 4$ & $0 \cdot 57$ \\
Geotextile & $3 \cdot 06$ & $217 \cdot 3$ & 1 & $130 \cdot 5$ & $0 \cdot 34$ \\
Clay & 19144 & $3 \cdot 5$ & 958 & $2038 \cdot 4$ & $5 \cdot 24$
\end{tabular}

Table 4. Carbon dioxide emissions from road transport of materials 
Solution

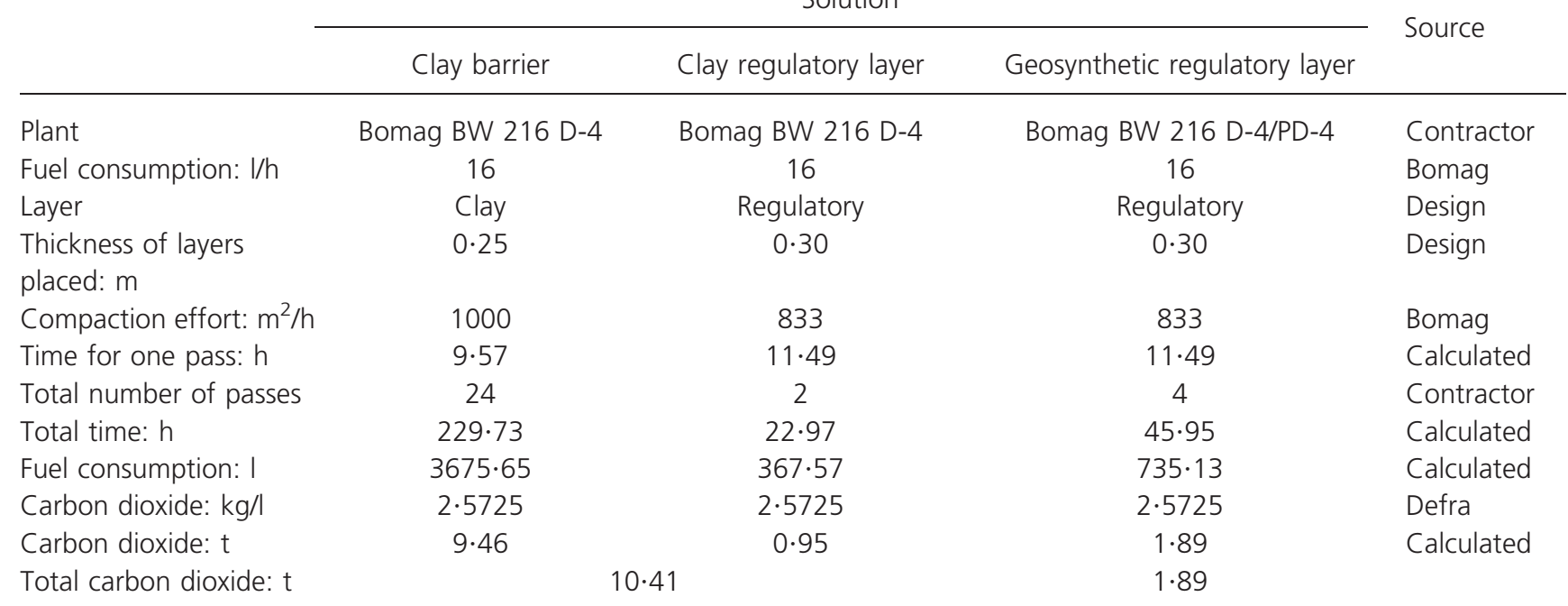

Table 5. Data employed in calculation of total construction carbon dioxide emissions

solution. This result was expected because construction of a clay cap requires significant compaction effort and the transport of a large mass of material. The results help to demonstrate where the largest emissions are generated and clearly show that the geosynthetic solution is more sustainable even if the clay for the cap was available on site (i.e. with no transport emissions). In this particular case study the clay was sourced from a location close to the site $(3.5 \mathrm{~km})$. However, in many cases, the clay would have to be sourced from larger distances and hence the transport-related emissions for clay are actually low for this case study. The calculation of construction-related emissions is important as it allows their contribution to the overall solution emissions to be understood; in the clay solution, these were more than $10 \mathrm{t}$ carbon dioxide.

The geosynthetic solution was employed in the actual design and it was selected due to its cost and time benefits. However, this study shows that it was also the more sustainable solution and, with the help of these findings, the client could promote its environmental benefits. The results could also help clients achieve better scores on environmental ratings such as Ceequal (2010) and any environmental product declarations (BSI, 2012).

\section{Accuracy of the data}

In many cases where common construction materials are used, embodied carbon values from databases such as the one produced by Hammond and Jones (2008a) are accepted as the best available source. However, in studies where less conventional materials (e.g. geosynthetics, as in this case study) are used, there is a need for more accurate product-specific data. This study suggests that - for both solutions examined - the majority of carbon dioxide emissions came from the embodied carbon of the materials. This is expected for the geosynthetic solution due to the energy-intensive manufacturing process. It might be assumed that the embodied carbon of clay would be very small as it is simply excavated and then loaded for transport. This would be consistent with the values provided in the Inventory of Carbon \& Energy database. The value of $0.005 \mathrm{~kg}$ embodied carbon dioxide per $\mathrm{kg}(\mathrm{kg} \mathrm{CO} 2 \mathrm{e} / \mathrm{kg})$ was used for clay; this is the value stated for quarried aggregate, which is considerably smaller than the values for other quarried materials (Table 8). Had values for soil and general clay been used, this would have provided an even higher total embodied carbon for the clay solution. These values may seem suitable based on their classification, but they

\begin{tabular}{lcccccc}
\hline Solution & Wattage: $\mathrm{kW}$ & $\begin{array}{c}\text { Length of } \\
\text { welding: } \mathrm{m}\end{array}$ & $\begin{array}{c}\text { Speed of welding: } \\
\mathrm{m} / \mathrm{min}\end{array}$ & Total time: $\mathrm{h}$ & Fuel consumption: $1 / \mathrm{h}$ & Total fuel: I \\
\hline Geosynthetic & 1.8 & 2120 & $2 \cdot 5$ & $14 \cdot 13$ & 0.682 & $9 \cdot 64$
\end{tabular}

Table 6. Fuel consumption of fusion welding 
Raja, Dixon, Fowmes, Frost and

\section{Solution}

Carbon dioxide emissions: $\mathrm{t}$

\begin{tabular}{|c|c|c|c|c|}
\hline & Transport & Embodied & Construction & Total \\
\hline Clay & $5 \cdot 24$ & $95 \cdot 72$ & $10 \cdot 40$ & $111 \cdot 37$ \\
\hline Geosynthetic & 1.09 & $29 \cdot 20$ & 1.92 & $32 \cdot 20$ \\
\hline
\end{tabular}

Table 7. Total emissions produced by both solutions

include LCA processes such as crushing and screening, which would not be associated with the clay used in this case study.

\subsection{Embodied carbon analysis for clay}

The aim of this part of the analysis was to calculate an embodied carbon value for clay and compare it to the value employed in the case study. In order to calculate a comparable value, the same LCA boundaries of cradle to gate had to be used. To meet this criterion, the calculations included three key LCA stages excavation, loading of road-going vehicle and transport to site exit. The emissions generated for these processes were calculated using data provided by an earthworks contractor, as summarised in Table 9.

The calculated value for embodied carbon for the clay $(0 \cdot 0003 \mathrm{t}$ $\mathrm{CO}_{2 \mathrm{e}} / \mathrm{t}$ ) was considerably lower than the Inventory of Carbon \& Energy database quarried aggregate value of $0.005 \mathrm{t} \mathrm{CO}_{2 \mathrm{e}} / \mathrm{t}$. It was also much lower than the values for other quarried materials (Table 8) that could have been used in the case study to represent the embodied carbon of the clay material. The difference between the calculated values and those listed in
Table 8 may be due to the fact that the Inventory of Carbon \& Energy database includes processes that are not relevant for clay (e.g. crushing and screening). Therefore, although using database values such as those for quarried aggregates may be convenient, the embodied carbon value calculated in this analysis shows that it may not be the most reliable approach, thus highlighting the importance of attention to detail in LCA comparisons.

\subsection{Impact of clay embodied carbon analysis on case study results}

The sensitivity of the case study results to possible clay embodied carbon values is illustrated in Figure 4. The use of the calculated embodied carbon value results in a reduction of around $90 \mathrm{t}$ carbon dioxide compared with use of the Inventory of Carbon \& Energy database value. Using the lower value makes a considerable difference, resulting in the clay capping solution being found to be more sustainable for this application (see Figure 5). It is considered that the calculated clay embodied carbon value is more reliable than the Inventory of Carbon \& Energy database value for material

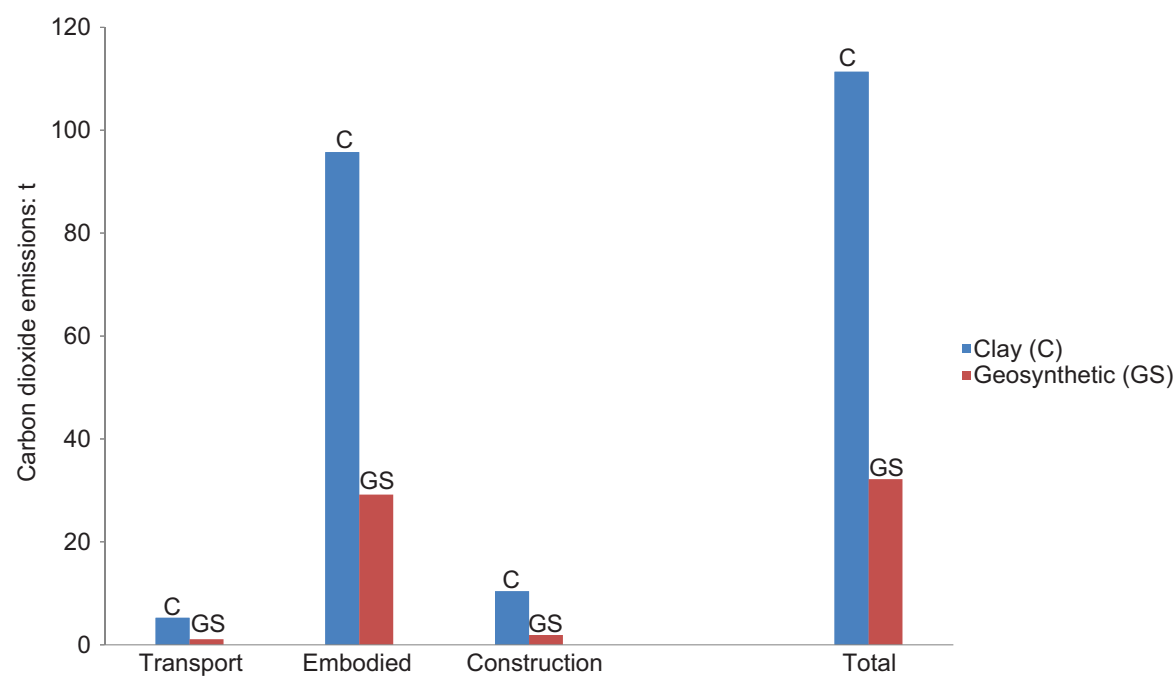

Figure 3. Total carbon dioxide emissions for the two solutions 
Comparison of carbon dioxide

emissions for two landfill

capping layers

Raja, Dixon, Fowmes, Frost and

Assinder
Embodied carbon:

$\mathrm{kg} \mathrm{CO} 2 \mathrm{e} / \mathrm{kg}$

\begin{tabular}{ll}
\hline Quarried aggregate & 0.005 \\
Recycled aggregate & 0.005 \\
Marine aggregate & 0.008 \\
Bitumen & 0.490 \\
Bricks & 0.240 \\
Clay: general (simple baked products) & 0.240 \\
Sand & 0.005 \\
Soil: general/rammed soil & 0.024 \\
Stone: general & 0.079 \\
Granite & 0.700 \\
Limestone & 0.090 \\
Sandstone & 0.060 \\
Shale & 0.002
\end{tabular}

Table 8. ICE database embodied carbon values of quarried materials (Hammond and Jones, 2008a)

that is excavated and transported without the need for additional processing, which is often the case in materials used in landfill liner and capping applications.

This analysis has shown that the ranking of design options in terms of carbon dioxide emissions can be dependent on the source and accuracy of material embodied carbon data. In this study, the geosynthetic solution is more sustainable if Inventory of Carbon \& Energy database embodied carbon values are used for the clay, but using calculated embodied carbon values for the clay reverses the ranking. In certain cases, when clay is available on site or only has to be transported a short distance (as in this case study), it may be both more economical and more sustainable to employ the clay solution. Based on this case study and the calculated embodied carbon value of clay, Figure 6 shows at what transport distance the use of the geosynthetic solution would be more sustainable in terms of carbon dioxide emissions. In this case study, if the clay had been imported from a distance of $11 \mathrm{~km}$ or more, the geosynthetic solution would be more sustainable. This is, however, still a relatively short distance for many sites and the distances they typically import clay from. Furthermore, this comparison did not consider the relative cost of the two solutions and the distance of clay transport may well influence the selection of the design option based on cost.

\section{Conclusion}

Carbon dioxide emissions for two commonly employed containment solutions in the landfill industry were compared. The aim of the study was not only to provide a comparison of the carbon dioxide emissions but also to illustrate the importance of applying rigorous methodology and accurate data collection. With sustainability being given increasing importance in construction, it is essential to accurately forecast potential carbon dioxide savings by employing a robust approach. Selection of a design will be influenced by economic constraints, but in many cases achieving both sustainability and economic benefits is not mutually exclusive.

The original geosynthetic design for this case study site was found to be more sustainable than an alternative clay solution. This conclusion was based on embodied carbon data commonly employed in the UK. However, the value of embodied carbon of the clay compared with construction- and transport-related emissions was questionable. With no embodied carbon value for clay fill in the Inventory of Carbon \& Energy database (Hammond and Jones, 2008a), a designer has to select a value for general quarried materials.

In order to investigate the accuracy of the clay input values, further analysis of the embodied carbon of clay fill was carried out. The analysis involved calculating an embodied carbon value for clay directly from contractor data. The calculated value was considerably lower than the original value employed in the case study and also much lower than the values for other quarried materials in the Inventory of Carbon \& Energy

\begin{tabular}{|c|c|c|c|c|c|}
\hline Process & Plant & Details & $\begin{array}{l}\text { Fuel consumption: } \\
\qquad 1 / \mathrm{t}\end{array}$ & $\begin{array}{l}\text { Embodied carbon: } \\
\qquad \mathrm{CO}_{2 \mathrm{e}} / \mathrm{t}\end{array}$ & Source \\
\hline $\begin{array}{l}\text { Excavation and } \\
\text { loading }\end{array}$ & $\begin{array}{l}\text { Komatsu PC450 } \\
(45 \mathrm{t})\end{array}$ & $\begin{array}{l}10 \mathrm{~h} \text { taken } 2800 \mathrm{~m}^{3}(5180 \mathrm{t} \text { ) } \\
\text { clay (bulk density of } 1.85 \mathrm{Mg} / \\
\left.\mathrm{m}^{3}\right) \text { moved }\end{array}$ & 0.087 & $0 \cdot 000224$ & $\begin{array}{l}\text { Contractor } \\
\text { Defra }(2011)\end{array}$ \\
\hline Shifting & $\begin{array}{l}20 \text { t road-going } \\
\text { dumper truck }\end{array}$ & $\begin{array}{l}0.8 \mathrm{~km} \text { journey to } \\
\text { site exit ( } 1.6 \mathrm{~km} \text { roundtrip) }\end{array}$ & 0.024 & 0.00006 & $\begin{array}{l}\text { DfT }(2012) \\
\text { Defra }(2011) \\
\text { Contractor }\end{array}$ \\
\hline
\end{tabular}

Table 9. Data and calculation of clay embodied carbon 


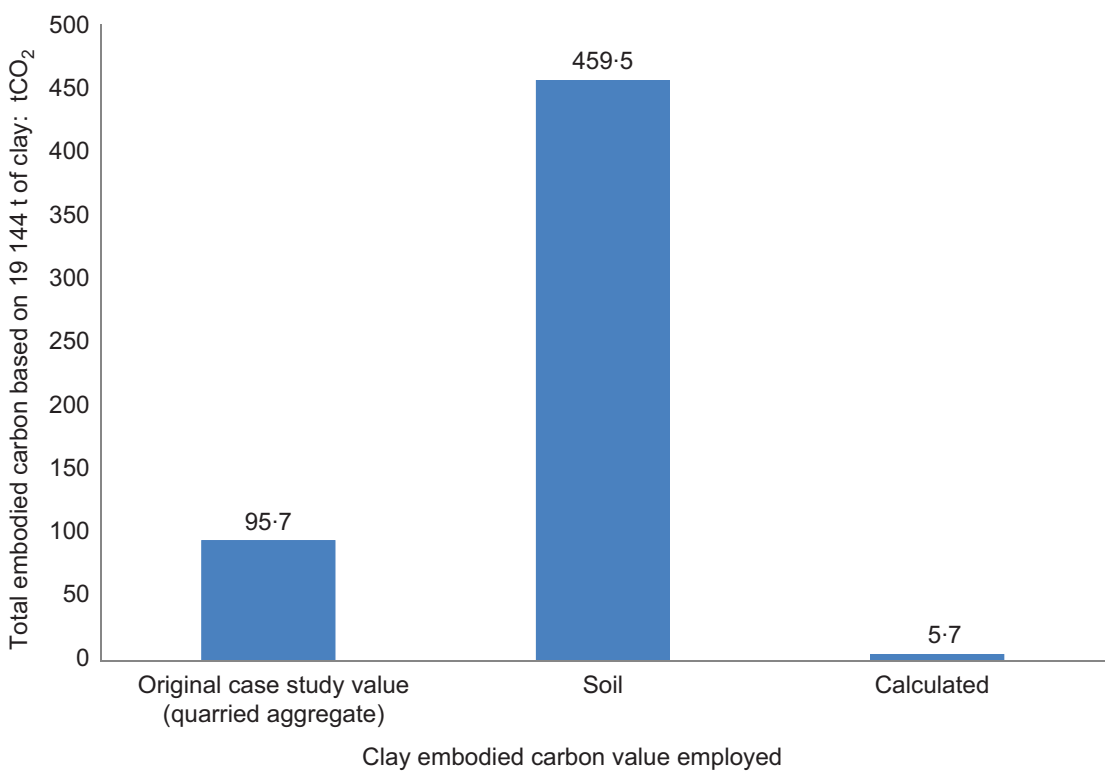

Figure 4. Variance of total embodied carbon due to clay input data

database. The use of this revised value in the case study had a major effect on the results, making the clay solution a more sustainable option than the geosynthetic solution.

In this particular case study, the transport distance of the clay fill was very short and thus transport-related carbon dioxide emissions were minimised. However, many sites import clay from greater distances, meaning that using geosynthetics to form the barrier layer will be a more sustainable solution. If the clay in this case study had been imported from a distance greater than $11 \mathrm{~km}$, the geosynthetic solution would have generated lower carbon dioxide emissions.

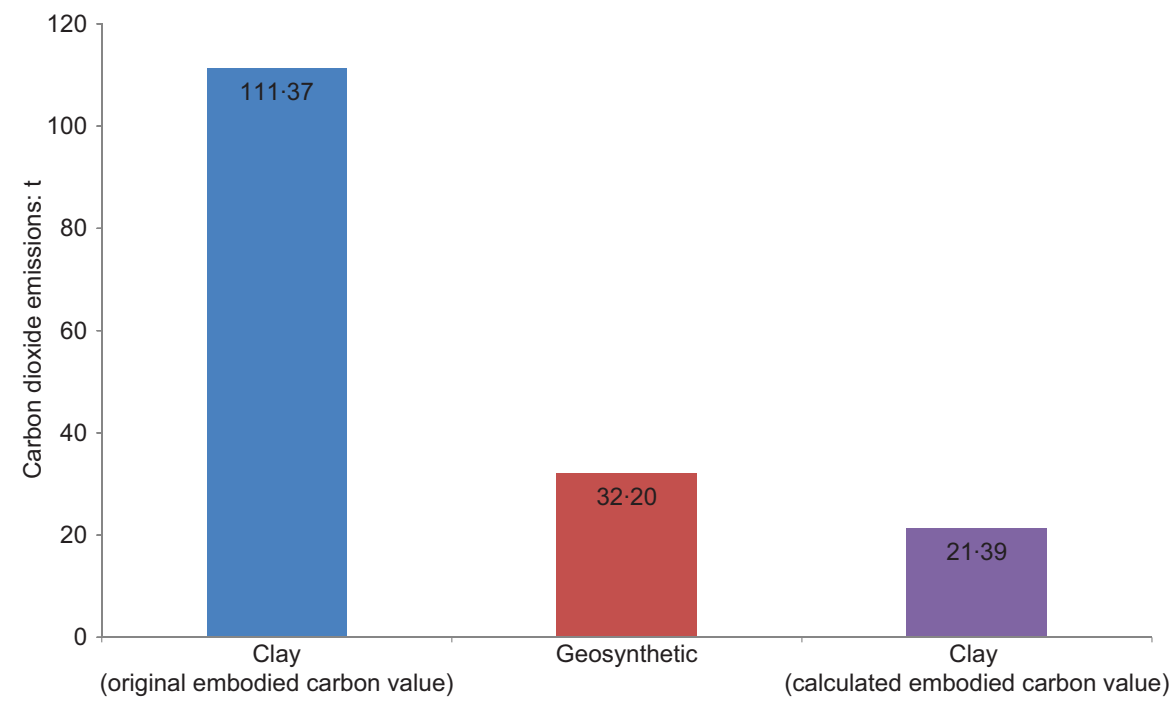

Figure 5. Comparison of total carbon dioxide emissions produced by each solution 
Comparison of carbon dioxide

emissions for two landfill

capping layers

Raja, Dixon, Fowmes, Frost and

Assinder

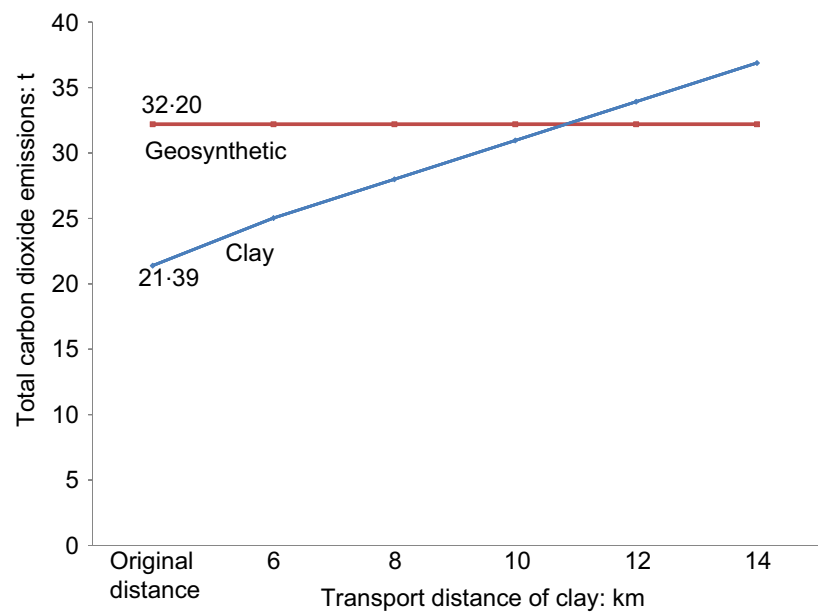

Figure 6. Effect of transport distance of clay on overall emissions

The cradle to end-of-construction LCA approach detailed in this paper can be used to compare the sustainability (as defined in this study by carbon dioxide emissions) of geotechnical design options with and without geosynthetic elements. The need for accurate input data such as embodied carbon values is, however, highlighted by the case study. Inaccurate data or values based on assumptions can affect the overall results by a significant amount, making one solution seem more sustainable than another. Work is ongoing to review and revise geosynthetic embodied carbon data and to develop further case studies for reinforcement, drainage and pavement applications.

\section{Acknowledgements}

This paper was completed as part of an engineering doctorate project being carried out at the Centre for Innovative and Collaborative Construction Engineering (CICE), Loughborough University. The authors would like to acknowledge the UK Chapter of the International Geosynthetics Society, CICE, Loughborough University and the Engineering and Physical Sciences Research Council (EPSRC), which collectively funded this project.

\section{REFERENCES}

BERR (Department for Business, Enterprise \& Regulatory Reform) (2008) HM Government Strategy for Sustainable Construction. HM Government, London, UK. BIS (Department for Business, Innovation \& Skills) (2010) Estimating the Amount of $\mathrm{CO}_{2}$ Emissions that the Construction Industry can Influence: Supporting Material for the Low Carbon Construction IGT Report. HM Government, London, UK.

BIS (2013) Construction 2025: Industrial Strategy for
Construction - Government and Industry in Partnership. HM Government, London, UK.

Bomag (2013) Single Drum Vibratory Rollers BW 216 D-4, BW 216 PD-4 - Performance Data. See https://bsa.bomag.com/ bsa/boo/pdf_files/PRE58262001_Sa05.pdf (accessed 15/11/ 2013).

BSI (2012) BS EN 1580: 2012: Sustainability of construction works - environmental product declarations - core rules for the product category of construction products. BSI, London, UK.

Ceequal (2010) Ceequal Assessment Manual for Projects in the $U K$ and Ireland, Version 4.1. Ceequal, London, UK.

Climate Change Act 2008 (2008) Elizabeth II. Chapter 27. The Stationery Office, London, UK.

Crishna N, Banfill PFG and Goodsir S (2011) Embodied energy and $\mathrm{CO}_{2}$ in UK dimension stone. Resources, Conservation and Recycling 55(12): 1265-1273.

Defra (Department for Environment, Food and Rural Affairs) (2011) Guidelines to Defra's GHG Conversion Factors for Company Reporting, Version 1.2. Defra, London, UK.

DfT (Department for Transport) (2012) Fuel Consumption by HGV Vehicle Type in Great Britain, 1993 to 2010. Table RFS0141. Domestic road freight activity (RFSO1). See https://www.gov.uk/government/statistical-data-sets/ rfs01-goods-lifted-and-distance-hauled (accessed 25/11/ 2013).

Hammond GP and Jones $\mathrm{Cl}$ (2008a) Inventory of (Embodied) Carbon \& Energy (ICE). Department of Mechanical Engineering, University of Bath, UK.

Hammond GP and Jones Cl (2008b) Embodied energy and carbon in construction materials. Proceedings of the Institution of Civil Engineers - Energy 161(2): 87-98

Hardy Diesel (2013) Diesel Generator Fuel Burn Calculator. See http://www.hardydiesel.com/generator-fuelconsumption-calculator.html (accessed 10/11/2013).

Heerten G (2012) Reduction of climate-damaging gases in geotechnical engineering practice using geosynthetics. Geotextiles and Geomembranes 30: 43-49.

Heerten G and Koerner RM (2008) Cover systems for landfills and brownfields. Journal of Land Contamination and Reclamation 16(4): 343-356.

IGT (Innovation and Growth Team) (2010) Low Carbon Construction IGT: Final Report. Department for Business, Innovation and Skills, London, UK, Report BIS/ $11 / 10 / \mathrm{NP}$

Kiani M, Parry T and Ceney H (2008) Environmental life-cycle assessment of railway track beds. Proceedings of the Institution of Civil Engineers - Engineering Sustainability 161(2): 135-142.

Koerner RM and Daniel DE (1997) Final Covers for Solid Waste Landfills and Abandoned Dumps. ASCE Press, Reston, VA, USA. 
Raja, Dixon, Fowmes, Frost and

Popov V (2005) A new landfill system for cheaper landfill gas purification. Renewable Energy 30(7): 1021-1029.

Royal Society (2010) Climate Change: A Summary of the Science. Royal Society, London, UK.

Silicon Instrumentation (2013) Astro Hot Wedge Welding Machine - Technical Data. See http://www.siliconinst.com/ catalog/astro-p-46.html (accessed 10/11/2013).
Stucki M, Büsser S, Itten R, Frischknecht R and Wallbaum H (2011) Comparative Life Cycle Assessment of Geosynthetics versus Conventional Construction Materials. European

Association of Geosynthetic Manufacturers, Mulhouse, France.

Wrap (2010) Sustainable Geosystems in Civil Engineering Applications. Wrap, Banbury, UK, Project MRF116.

\section{WHAT DO YOU THINK?}

To discuss this paper, please email up to 500 words to the editor at journals@ice.org.uk. Your contribution will be forwarded to the author(s) for a reply and, if considered appropriate by the editorial panel, will be published as discussion in a future issue of the journal.

Proceedings journals rely entirely on contributions sent in by civil engineering professionals, academics and students. Papers should be $2000-5000$ words long (briefing papers should be 1000-2000 words long), with adequate illustrations and references. You can submit your paper online via www.icevirtuallibrary.com/content/journals, where you will also find detailed author guidelines. 